\title{
Basal Forebrain Lactate Release and Promotion of Cortical Arousal during Prolonged Waking Is Attenuated in Aging
}

\author{
Henna-Kaisa Wigren, Kirsi-Marja Rytkönen, and Tarja Porkka-Heiskanen \\ Institute of Biomedicine/Physiology, Biomedicum Helsinki, University of Helsinki, FIN-00014 Helsinki, Finland
}

The wake-promoting basal forebrain $(\mathrm{BF})$ is critically involved in sustaining cortical arousal. In the present study, we investigated how aging affects the capacity of the $\mathrm{BF}$ to cope with continuous activation during prolonged waking. Increased neuronal activity induces lactate release in the activated brain area, and $\mathrm{BF}$ stimulation increases cortical arousal. We used in vivo microdialysis to measure lactate levels in the BF, and electroencephalography (EEG) to measure cortical arousal, during $3 \mathrm{~h}$ sleep deprivation (SD) in three age groups of rats. Lactate increased during SD in young but not in aged (middle-aged and old) rats. The increase in high-frequency (HF) EEG theta power $(7-9 \mathrm{~Hz})$, a marker of cortical arousal and active waking, was attenuated in the aged. Furthermore, a positive correlation between BF lactate release and HF EEG theta increase was found in young but not in aged rats. We hypothesized that these age-related attenuations result from reduced capacity of the $\mathrm{BF}$ to respond to increased neuronal activation. This was tested by stimulating the BF with glutamate receptor agonist NMDA. Whereas $\mathrm{BF}$ stimulation increased waking in young and old rats, lactate increase and the HF EEG theta increase were attenuated in the old. Also, the homeostatic increase in sleep intensity after SD was attenuated in aged rats. Our results suggest that an age-related attenuation in BF function reduces cortical arousal during prolonged waking. As the quality of waking is important in regulating the subsequent sleep, reduced cortical arousal during SD may contribute to the age-related reduction in sleep intensity.

\section{Introduction}

Wakefulness is a metabolic challenge for brain regions responsible for arousal (Porkka-Heiskanen et al., 2002; Cirelli, 2006; Vyazovskiy et al., 2008), and it has been suggested that during prolonged waking supplementary energy stores are used to sustain neuronal activity (Benington and Heller, 1995). Aging is associated with changes in sleep-wake architecture, including vigilance state fragmentation (i.e., the inability to maintain prolonged periods of wake and sleep), and attenuated homeostatic sleep response to sleep deprivation (Carskadon et al., 1982; Buysse et al., 1992; Ohayon et al., 2004; Cajochen et al., 2006). In addition, reduced capacity of the brain cells to cope with challenges, such as increased activity or energy demand, is reported during aging (Toescu and Xiong, 2004). Yet, it is not well known how these age-related cellular changes affect sleep-wake regulation.

The cholinergic basal forebrain (BF), an important area in regulation of wakefulness and cortical arousal (Jones, 2008; Parikh and Sarter, 2008), is selectively sensitive to both prolonged waking (Basheer et al., 2004) and to aging (Schliebs and Arendt, 2006). Healthy aging is associated with morphological and functional changes in the BF (Armstrong et al., 1993; Sarter and

Received Dec. 3, 2008; revised July 23, 2009; accepted Aug. 8, 2009.

This study was supported by the Academy of Finland, the Finnish Graduate School of Neuroscience, and European Union Grants LSHM-CT-2005-518189 and MCRT-CT-2004-512362. We thank Dr. Ernst Mecke, Pirjo Saarelainen, Sari Levo-Siitari, and Natalia Gass for their excellent assistance and technical help.

Correspondence should be addressed to Dr. Henna-Kaisa Wigren, Institute of Biomedicine/Physiology, Biomedicum Helsinki, University of Helsinki, P.0. Box 63, FIN-00014 Helsinki, Finland. E-mail: henna-kaisa.wigren@ helsinki.fi.

DOI:10.1523/JNEUROSCI.5773-08.2009

Copyright $\odot 2009$ Society for Neuroscience $\quad$ 0270-6474/09/2911698-10\$15.00/0
Bruno, 2004; Murchison and Griffith, 2007; Baskerville et al., 2008). During prolonged waking, the wake-promoting BF cells are continuously active, which increases energy demand (Wigren and Porkka-Heiskanen, 2009), extracellular levels of nitric oxide (Kalinchuk et al., 2006b), and energy metabolites adenosine and lactate (Porkka-Heiskanen et al., 1997; Kalinchuk et al., 2003).

Several lines of evidence now indicate that lactate, released from astrocytes in response to enhanced or sustained neuronal activity, is used as an energy fuel in active neurons (Pellerin et al., 2007). This activity-dependent lactate release has been detected in the activated brain areas during sensory and cognitive stimulations in humans (Prichard et al., 1991; Sappey-Marinier et al., 1992; Urrila et al., 2003) or during behavioral or experimental neuronal activation in animals (Kuhr and Korf, 1988; Hu and Wilson, 1997; Ros et al., 2006; Caesar et al., 2008). In the BF, extracellular lactate level increases during sleep deprivation (SD) when rats are kept awake by presentation of novel objects (Kalinchuk et al., 2003), which stimulates active waking (Huber et al., 2007) and electroencephalographic (EEG) theta (5-9 Hz) activity (Vyazovskiy and Tobler, 2005; Wigren et al., 2007; Kaur et al., 2008).

Theta activity in rodents is generally regarded as a marker of cortical arousal (Vinogradova, 1995; Kahana et al., 2001) and particularly the higher theta frequencies $(\sim 7-9 \mathrm{~Hz})$ correlate with active wake (Maloney et al., 1997; Young and McNaughton, 2008). Glutamatergic stimulation of the BF increases active waking, high-frequency (HF) EEG theta power and BF lactate level (Cape and Jones, 2000; Wigren et al., 2007), indicating that the lactate increase in the BF follows from increased neuronal activity occurring during EEG theta enriched active waking. 
We tested the hypothesis that BF neuronal activity and the following lactate increase are important in sustaining waking and cortical arousal during SD, and that in aging this mechanism is attenuated. Using in vivo microdialysis, we measured BF lactate levels during $3 \mathrm{~h} \mathrm{SD}$ and during sustained BF stimulation (NMDA infusion) in three age groups of rats (young, middleaged, old). EEG was recorded to monitor vigilance states and cortical arousal during and after the experiments.

\section{Materials and Methods}

\section{Animals and surgery}

All animal procedures were approved by the University of Helsinki Ethical Committee for Animal Experiments and by the Regional Committee of the State Provincial Office and performed according to applicable national and European Union legislation. Three age groups of male Hannover Wistar rats: young (Y) (3-4 months; $362 \pm 7 \mathrm{~g} ; n=17)$, middleaged (M) (12-14 months; $561 \pm 24 \mathrm{~g} ; n=11)$, and old $(\mathrm{O})(23-25$ months; $676 \pm 35 \mathrm{~g} ; n=13$ ) were housed on a $12 \mathrm{~h} \mathrm{light/dark} \mathrm{cycle} \mathrm{(lights}$ on at 8:30 A.M.) at constant temperature $\left(+22 \pm 1^{\circ} \mathrm{C}\right)$. Food and water were provided ad libitum. Animals were gradually habituated to handling at least 1 week before surgery.

Under general anesthesia $(2.5 \mathrm{mg} / \mathrm{kg}$, i.p., diazepam; $0.4 \mathrm{mg} / \mathrm{kg}$, i.p., medetomidine; $60 \mathrm{mg} / \mathrm{kg}$, i.p., ketamine; dosages were adjusted according to age), rats were placed in a stereotaxic instrument (David Kopf Instruments) and implanted with the following: (1) chronic epidural EEG electrodes and dorsal nuchal electromyogram (EMG) electrodes for studying vigilance states and EEG activity, and (2) with microdialysis guide cannula (CMA 11 guide; CMA/Microdialysis) for subsequent insertion of microdialysis probe. The bipolar screw EEG electrodes were placed frontoparietally to the skull: $2 \mathrm{~mm}$ rostral, $2 \mathrm{~mm}$ lateral from bregma, and $4 \mathrm{~mm}$ rostral, $1 \mathrm{~mm}$ lateral from lambda. The microdialysis guide cannula was inserted unilaterally $2 \mathrm{~mm}$ above the basal forebrain area: $0.3 \mathrm{~mm}$ posterior, $2 \mathrm{~mm}$ lateral, and $5 \mathrm{~mm}$ ventral to bregma. The guide cannula and the electrode connector were fixed to the skull with acrylic dental cement.

After surgery, rats were single-housed in Plexiglas boxes and allowed to recover from 1 up to 2.5 weeks. They were then connected to flexible counterbalanced cables for EEG/EMG recording and habituated to recording cables for 2-3 d. The experiments were not started until their behavior and sleep-wake cycle had normalized.

\section{In vivo microdialysis and EEG/EMG recording}

We used in vivo microdialysis for collection of lactate samples and for glutamatergic stimulation of the $\mathrm{BF}$ [reverse microdialysis of $0.3 \mathrm{~mm}$ NMDA (Sigma-Aldrich) in perfusion fluid] as in the studies by Kalinchuk et al. (2003) and Wigren et al. (2007).

Twenty hours before the first experiment, microdialysis probes (CMA 11 probe; membrane length, $2 \mathrm{~mm}$; diameter, $0.24 \mathrm{~mm}$; mean recovery rate, $10 \%$; CMA/Microdialysis) were lowered through the guide cannula into the BF. On the day of the experiments between 9:00 and 10:00 A.M., rats were connected to the EEG/EMG recording cables and to the in vivo microdialysis tubing. Tubing were connected to the microdialysis syringe pump (CMA/Microdialysis) and continuous perfusion $(1 \mu \mathrm{l} / \mathrm{min})$ of artificial CSF (aCSF) (147 mm NaCl, $3 \mathrm{~mm} \mathrm{KCl}, 1.2 \mathrm{CaCl}_{2}, 1 \mathrm{~mm} \mathrm{MgCl}$ ) took place throughout the $6 \mathrm{~h}$ in vivo microdialysis period between 10:00 A.M. and 4:00 P.M.

The EEG/EMG signal was fed to an eight-channel digital amplifier (Cyber Amp 380; Molecular Devices), amplified (gain, 10,000), analogically filtered (high pass, $0.4 \mathrm{~Hz}$; low pass, $40 \mathrm{~Hz}$ ), digitized at 104 $\mathrm{Hz}$ with 1401 unit (CED), monitored on-line during the experiments, and stored on a computer using Spike2 software (CED) for additional off-line analysis.

\section{Experiments}

For each experiment, collection of $30 \mathrm{~min}(30 \mu \mathrm{l})$ samples was started at 10:00 A.M. and continued for $6 \mathrm{~h}$ until 4:00 P.M. (together, 12 samples were collected). Samples were stored at $-80^{\circ} \mathrm{C}$. At the end of the microdialysis period, animals were disconnected from the microdialysis tubing while the EEG/EMG recording was continued until the next morning
(9:00 A.M.). During the first experimental day [baseline day (BL)], animals were left undisturbed (except for connecting/disconnecting of microdialysis tubing in the beginning and end of the microdialysis period) to allow spontaneous sleep-wake behavior to occur. On the following days, two types of experiments were performed: either sleep deprivation or glutamatergic stimulation of the BF. Before treatments, aCSF perfusion alone was performed for 2-3 h to collect samples for the determination of the pretreatment lactate level. Between 9:00 and 10:00 A.M. of the experimental days, animals were connected to microdialysis tubing and therefore EEG data from this time point were not recorded.

Prolonged waking/SD. To keep animals awake and to evoke active waking and exploratory behavior; novel objects (including wooden blocks, new bedding material, and stretchable strings) were introduced to rat cages. To increase sleep pressure and to induce subsequent recovery sleep, SD was continued for $3 \mathrm{~h}$. Whenever animals appeared sleepy or slow waves were visible in the EEG, new objects were introduced and/or the cage was gently tapped. This method is referred to as SD by gentle handling in the literature (Franken et al., 1991). After the end of the $3 \mathrm{~h}$ treatment period, animals were left undisturbed for recovery sleep recording until the next morning. If an animal was used for both experiments, SD was always performed first and minimum $48 \mathrm{~h}$ was allowed between experiments.

Glutamatergic stimulation (NMDA) of the BF. To study the mechanisms of lactate release in the $\mathrm{BF}$ and to activate the animals without the presence of the experimenter, the BF was stimulated with NMDA [in vivo microdialysis fluid (aCSF) was switched to $0.3 \mathrm{~mm}$ NMDA in aCSF for 3 $\mathrm{h}$. At the end of NMDA treatment, microdialysis fluid was switched back to aCSF for $1 \mathrm{~h}$ to allow wash-off time before disconnection of the microdialysis tubing and start of undisturbed recovery sleep recording. Stimulation of the BF with this concentration has previously been shown to increase neuronal activation, to increase cortical arousal, to induce waking, to promote exploratory behavior, and to increase waking EEG theta power (Page et al., 1993; Manfridi et al., 1999; Cape and Jones, 2000; Wigren et al., 2007). NMDA-induced waking also increases homeostatic sleep pressure as it was previously shown to induce subsequent recovery sleep (Wigren et al., 2007).

\section{HPLC}

Microdialysis samples were assayed for lactate as in the study by Hallström et al. (1989) using HPLC system (Shimadzu) for separation, and UV spectrophotometer (Waters Corporation) for detection. Detection limit/signal-to-noise ratio was $10 \mu \mathrm{m} / 3: 1$, respectively (Grob, 1985). Lactate concentration was determined by comparing sample peak areas with those of standards using CLASS VP software (Shimadzu). To minimize day-to-day variation, baseline lactate concentrations for each animal were determined as a mean value of samples collected during the baseline day and during the pretreatment periods of the treatment days. To detect lactate responses to SD or to glutamatergic stimulation, samples collected during the treatments were normalized to the samples collected from the pretreatment period of the same day for each individual animal. To correlate lactate release with EEG theta activity during SD, individual $30 \mathrm{~min}$ samples (every other sample; together, six samples per rat) were normalized to the pretreatment level and matched with EEG data of the corresponding $30 \mathrm{~min}$ collection period. The dead volume of the microdialysis tubing was taken into consideration when matching samples with EEG data.

\section{Histological verification of probe location}

After the end of the experiments, animals received a lethal dose of pentobarbital $(100 \mathrm{mg} / \mathrm{kg})$. Color ink was injected through a modified microdialysis probe to mark the location of the probe tip. The brains were removed, frozen on dry ice, and stored at $-80^{\circ} \mathrm{C}$. Twenty micrometer coronal frozen sections were cut using a freezing microtome, stained with toluidine blue, coverslipped, and visually inspected under a light microscope to verify the location of the probe tip using rat brain atlas (Paxinos and Watson, 1998). Only those rats with probe locations in a close vicinity of the target area (BF) including horizontal diagonal band of Broca (HDB), substantia innominata (SI), magnocellular preoptic area 
(MCPO), lateral preoptic area (LPO) and the basal nucleus of Meynert (B) were included in the analysis. Probe tip locations are shown in Figure 1. Off-target experiments (probes outside the $\mathrm{BF}$ ) were not included in the present study as the site-specific (outside BF compared with $\mathrm{BF}$ probes) extracellular lactate increase during $3 \mathrm{~h} \mathrm{SD}$ in young rats has repeatedly been shown previously (Kalinchuk et al., 2003, 2006b).

\section{Scoring and analysis of vigilance states}

Before analysis, all EEG traces were digitally high-pass filtered $(0.8 \mathrm{~Hz}$ cutoff). We used semiautomatic scoring of slow-wave sleep (SWS) in $30 \mathrm{~s}$ epochs as in the studies by Kalinchuk et al. (2003) and Stenberg et al. (2003) to measure the overall distribution and amount of SWS (the $23 \mathrm{~h}$ sleep pattern) during the BL and experimental days. Rapid eye movement (REM) sleep was scored manually. Wake epochs and the number of state transitions (number of shifts among behavioral states: wake $\rightleftarrows$ SWS $\rightleftarrows$ REM $\rightarrow$ wake) were calculated from these two scores.

All the recordings that were used for power-spectral analysis (the microdialysis period between 10:00 A.M. and 4:00 P.M. and the subsequent $3 \mathrm{~h}$ postmicrodialysis recovery period) were scored manually in $5 \mathrm{~s}$ epochs with Spike2 sleep scoring script Sleepscore, version 1.01 (CED), according to standard criteria: SWS was recognized as high-amplitude EEG associated with lowvoltage EMG and presence of slow delta $(0.8-4 \mathrm{~Hz})$ oscillations in the EEG, REM sleep as low-amplitude, high-frequency EEG with absence of EMG and presence of prominent EEG theta $(5-9 \mathrm{~Hz})$, and waking as low-amplitude, high-frequency EEG with high-voltage EMG. Artifacts or epochs with mixed states were marked and excluded from power spectral analysis.

Two additional measures were applied to investigate the behavior of the rats during $\mathrm{SD}$ as follows.

Number of sleep bouts. Sleep bouts were defined as more than one $5 \mathrm{~s}$ epoch scored as SWS. As rats were always activated when they appeared sleepy or slow waves occurred in the EEG, this measure also reflects the number of interventions needed to keep the rats awake during SD.

Number of high EMG activity bouts. SD increases exploratory behavior and it is associated with increased movement (i.e., increased muscle activity). To control for the possible age differences in moving activity, we counted the number of high EMG activity bouts with a custom-made Spike2 script. The total EMG power (fast Fourier transformation routine in Spike2) of the $23 \mathrm{~h}$ EMG recording was calculated first and based on this mean value of the total EMG power, the script automatically scored the EMG data either as high activity or as low activity in $5 \mathrm{~s}$ epochs. Because a mean value of the total EMG power over the whole recording was used to define the threshold, only the high EMG activity bouts (e.g., when the rat was actively moving around) were determined as high activity. From most of the $23 \mathrm{~h}$ EMG recordings of the BL and SD, the script accurately recognized the activity period of the rats during the dark period and the SD period. Rats, in which these periods were not recognized by the script, were discarded from the analysis of activity bouts during SD.

\section{Power spectral analysis of the EEG}

EEG power (in square microvolts) spectra of the manually scored EEG data were generated in Spike2 (CED) separately for consecutive $5 \mathrm{~s}$ wake and SWS epochs [fast Fourier transform routine (FFT), 256; Hanning window, $0.4 \mathrm{~Hz}$ resolution] within a frequency range of $0.8-35 \mathrm{~Hz}$ and averaged over the time period that was investigated ( $6 \mathrm{~h}$ between 10:00 A.M. to 4:00 P.M. for the baseline, $3 \mathrm{~h}$ for the treatment periods, and $3 \mathrm{~h}$ for the posttreatment recovery periods of SD and NMDA). These spectra were always normalized to total power of the same recording period before additional analysis. To study the effects of treatments (SD, NMDA) compared with BL, the spectra of the $3 \mathrm{~h}$ treatment periods and the $3 \mathrm{~h}$ posttreatment periods were always compared and/or normalized to the corresponding spectra of the BL day. Waking theta power was defined as $5-9 \mathrm{~Hz}$ [low frequency (LF) theta as $5-7 \mathrm{~Hz}$; HF theta as 7-9 $\mathrm{Hz}]$ and gamma power as frequencies $>30 \mathrm{~Hz}$. We used waking EEG theta as a measure of cortical arousal and wake quality and calculated the ratio of HF theta versus LF theta because LF theta correlates with quiet waking and HF theta with active waking (Maloney et al., 1997; Young and McNaughton, 2008).

\section{SWS delta and recovery sleep}

Prolonged waking invariably leads to homeostatic recovery sleep response: increases in SWS duration and SWS delta power (Tobler and Borbély, 1990). To test whether treatments (SD, NMDA) induced recovery sleep, we calculated SWS delta power (defined as $0.8-4 \mathrm{~Hz}$ ) and SWS amount from the posttreatment EEG recordings and compared them with the corresponding time points of the BL day.

\section{Statistical analysis}

Statistical analyses were performed using SigmaStat 3.1 (SPSS Science Software). Statistics were applied (1) to study the effect of treatments (SD, NMDA) within an age group ("within an age group compari- 
A

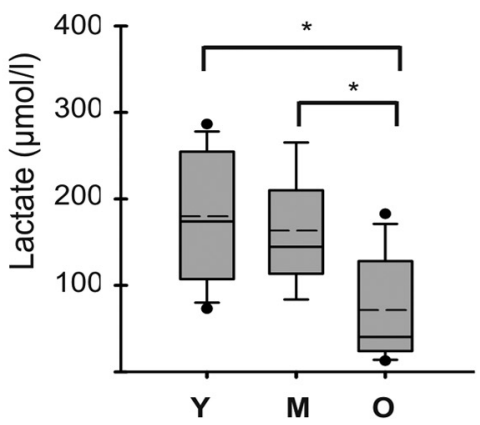

B

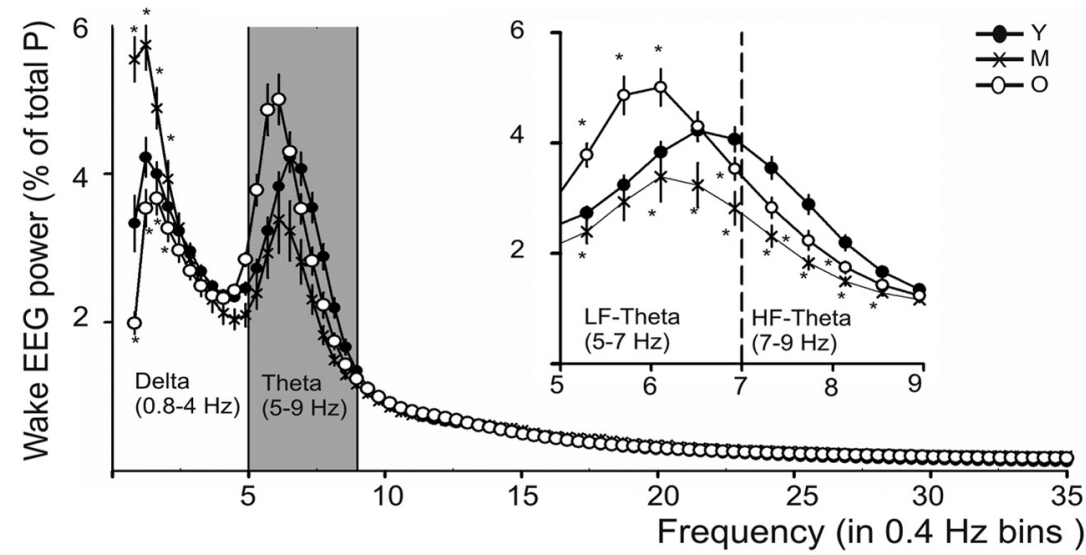

C

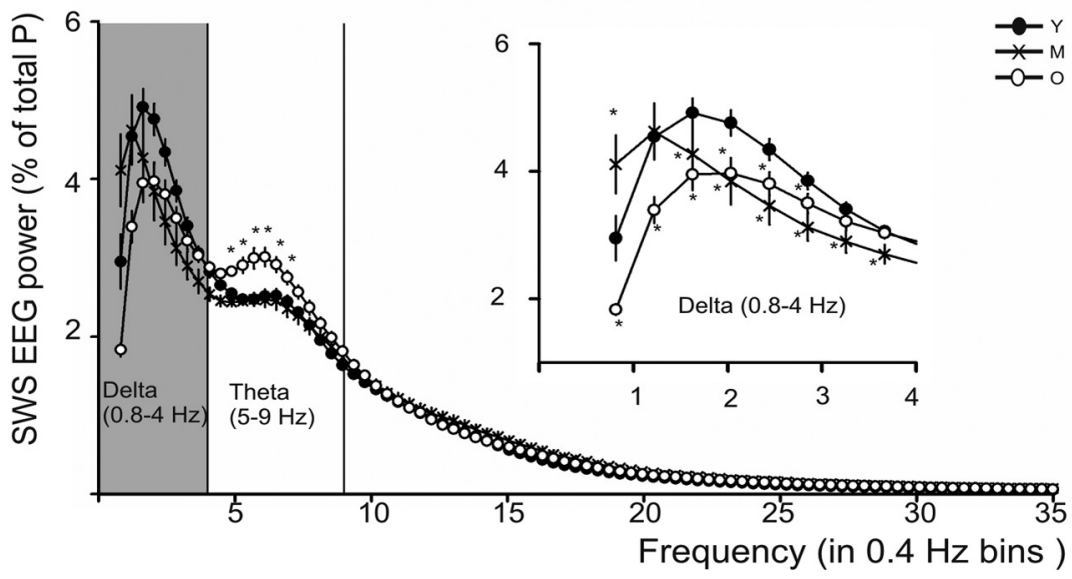

Figure 2. Baseline. $A, B F$ lactate. Boxplots show the BL lactate concentration (in micromoles per liter) in the BF of young (Y) $(n=17)$, middle-aged (M) $(n=9)$, and old (0) $(n=13)$ rats. To control for the day-to-day variation in lactate levels, mean lactate concentrations were calculated from all samples collected during BL in vivo microdialysis period as well as from samples collected during the pretreatment periods of the treatment days. Old rats had lower lactate concentration than middle-aged or young rats. Statistical significance between the age groups (one-way ANOVA followed by Holm-Sidak) is indicated with asterisks (*). Group mean concentration is denoted with dashed horizontal lines inside the boxes, whereas solid horizontal lines mark the median concentration. Outliers within an age group are shown as black dots. Error bars mark the \pm SEM level. $B, C$, EEG power spectra. To assess cortical arousal during the baseline in vivo microdialysis period (10:00 A.M. to 4:00 P.M.), we created vigilance state-specific mean EEG power spectra from the manually scored EEG epochs. The mean ( \pm SEM) EEG power (percentage of total power; $y$-axis) of wake $(\boldsymbol{B})$ and SWS $(\boldsymbol{C})$ is plotted for the entire spectral range (frequencies between 0.8 and $35 \mathrm{~Hz}$ in $0.4 \mathrm{~Hz}$ bins; $x$-axis). The frequency ranges, in which the major statistically significant differences (two-way repeated-measures ANOVA followed by Holm-Sidak) between the aged ( $M$ or 0 ) and the young were found, are highlighted with gray background panels and shown in a larger resolution in the top right panels. In the high-resolution image of $\boldsymbol{B}$, the LF theta $(5-7 \mathrm{~Hz})$ and the $\mathrm{HF}$ theta $(7-9 \mathrm{~Hz})$ are separated by a vertical dashed line. The individual $0.4 \mathrm{~Hz}$ frequency bins in which a statistical significance $(p<0.05)$ between the aged ( $\mathrm{M}$ or 0$)$ and the young was found are indicated with asterisks $\left({ }^{*}\right)$. Age groups are as follows: $\mathrm{Y}(\mathbf{O} ; n=17), \mathrm{M}(\mathrm{X} ; n=5), 0(\bigcirc ; n=13)$.

sons") and (2) to compare age groups ("between age groups comparisons"). Before comparing the effect of treatments between age groups, the data were normalized: the power spectra and the vigilance state counts were normalized to the corresponding time points of the BL day within an individual animal, whereas lactate levels of the treatment period were normalized to the pretreatment level within an individual animal.

For simple comparisons of independent variables, we used two-tailed Student's $t$ tests to compare two variables, or one-way ANOVA if more than two variables were compared. To isolate which variable(s) differed from the others, one-way ANOVA was followed by HolmSidak multiple-comparison procedure as a post hoc test. For simple comparisons of dependent variables, we used paired $t$ tests (two variables such as pretreatment vs treatment) or one-way repeated measures of ANOVA (more than two variables such as vigilance states in time series or EEG power in frequency bins). For combined analysis of independent and dependent variables, we used two-way repeated measures of ANOVA. In these analyses, the treatment or age was set as an independent variable and EEG measures (such as vigilance states in time series or power in frequency bins) were set as dependent variables. Holm-Sidak was used as a post hoc test. In case the data were not normally distributed, equivalent nonparametric tests were applied: one-way ANOVA was replaced with Kruskal-Wallis one-way ANOVA on ranks followed by Dunn's comparison. For correlation analysis, Pearson's product moment correlation was used. A value of $p<0.05$ was considered statistically significant. Data are shown as mean \pm SEM; statistical significances are denoted with hash symbols (\#) for the within an age group comparisons and with asterisks $\left(^{*}\right)$ for the between age group comparisons. Age groups are indicated as follows: young rats with Y (black circles; $)$ ); middleaged rats with $\mathrm{M}$ (crosses; $\times$ ), and old with $\mathrm{O}$ (open circles; $\bigcirc$ ).

\section{Results}

\section{Baseline}

The $23 \mathrm{~h}$ sleep-wake pattern

The $23 \mathrm{~h}$ (from 10:00 A.M. to 9:00 A.M.) baseline sleep-wake profile (percentage of time spent in SWS, in REM sleep, and the mean number of state transitions) in $1 \mathrm{~h}$ time bins can be found in supplemental Table 1 (available at www.jneurosci.org as supplemental material). A statistically significant reduction of SWS amount in the old $(n=13)$ compared with young $(n=$ 11) rats was found during the second, third, and fourth hour of the BL recording (two-way repeated-measures ANOVA with Holm-Sidak; $F_{(44)}=1.450 ; p=$ 0.032). However, most differences between age groups were found in the number of state transitions: the middle-aged and the old had more state transitions than the young (two-way repeatedmeasures ANOVA with Holm-Sidak; $\left.F_{(44)}=1.421 ; p=0.041\right)$.

Vigilance states during the $6 \mathrm{~h}$ in vivo microdialysis period All rats slept on average $60 \%$ of the time (SWS, $50 \pm 1 \%$; REM, $10 \pm 1 ; n=35$ ). Statistically significant differences between the 
age groups in the time spent in SWS, REM sleep, or wake (calculated as mean $6 \mathrm{~h}$ values) were not found (data not shown).

\section{BF lactate}

There was an age-dependent reduction in baseline lactate level (one-way ANOVA; $\left.F_{(2)}=10.118 ; p<0.001\right)$ : old rats $(n=$ 13) had lower lactate concentration than the middle-aged $(n=9)$ or young $(n=$ 17) (Holm-Sidak; $p=0.004$ and $p<$ 0.001 , respectively) (Fig. $2 A$ ). To control for day-to-day variation in lactate levels, mean BL lactate concentrations were calculated from all samples collected during the $\mathrm{BL}$ microdialysis period as well as from samples collected during the pretreatment periods of the treatment days.

\section{EEG power spectra of the in vivo}

microdialysis period

To assess cortical arousal during waking and sleep intensity during SWS, vigilance state-specific mean EEG power spectra (frequencies between 0.8 and $35 \mathrm{~Hz}$, in 0.4 $\mathrm{Hz}$ bins) were calculated by averaging over all the $5 \mathrm{~s}$ wake or SWS epochs within the $6 \mathrm{~h}$ in vivo microdialysis period, and the age groups were compared $\left(n_{\mathrm{Y}}=17\right.$; $\left.n_{\mathrm{M}}=5 ; n_{\mathrm{O}}=13\right)$. Statistically significant interactions between age and frequency in the wake EEG power (two-way repeatedmeasures ANOVA followed by HolmSidak; $\left.F_{(168)}=8.242 ; p<0.001\right)$ were found in the delta $(0.8-4.0 \mathrm{~Hz})$ and in theta $(5-9 \mathrm{~Hz})$ frequency ranges (Fig. $2 B$ ). The peak frequency of waking theta was $6.5 \mathrm{~Hz}$ in the young but had shifted to 6.1 $\mathrm{Hz}$ in the middle-aged and the old (Fig. $2 B$, right panel). Old rats also had more power in the LF theta range.

In the SWS EEG power, statistically significant interaction between age and frequency (two-way repeated-measures ANOVA followed by Holm-Sidak, $F_{(168)}$ $=5.133 ; p<0.001$ ) was found in the delta range between the old and the young, and between the middle-aged and the young (Fig. 2C, top right panel). In the theta range, differences were found between the young and the old (Fig. 2C, left panel).

\section{Sleep deprivation}

Before sleep deprivation, in vivo microdialysis samples were collected for the determination of the pretreatment lactate level. During this period, statistically significant differences between the age groups in the time spent in sleep or wake were not found (data not shown). During SD, rats were awake $95.7 \pm 1 \%$ of the time $(\mathrm{Y}, 98.6 \pm 0.6 \%, n=10 ; \mathrm{M}, 97.9 \pm 1.2, n=5 ; \mathrm{O}, 92.7 \pm 1.1$, $n=13)$.

\section{BF lactate}

In young rats, lactate concentration increased significantly during SD compared with the pretreatment level (paired $t$ test; $n=$
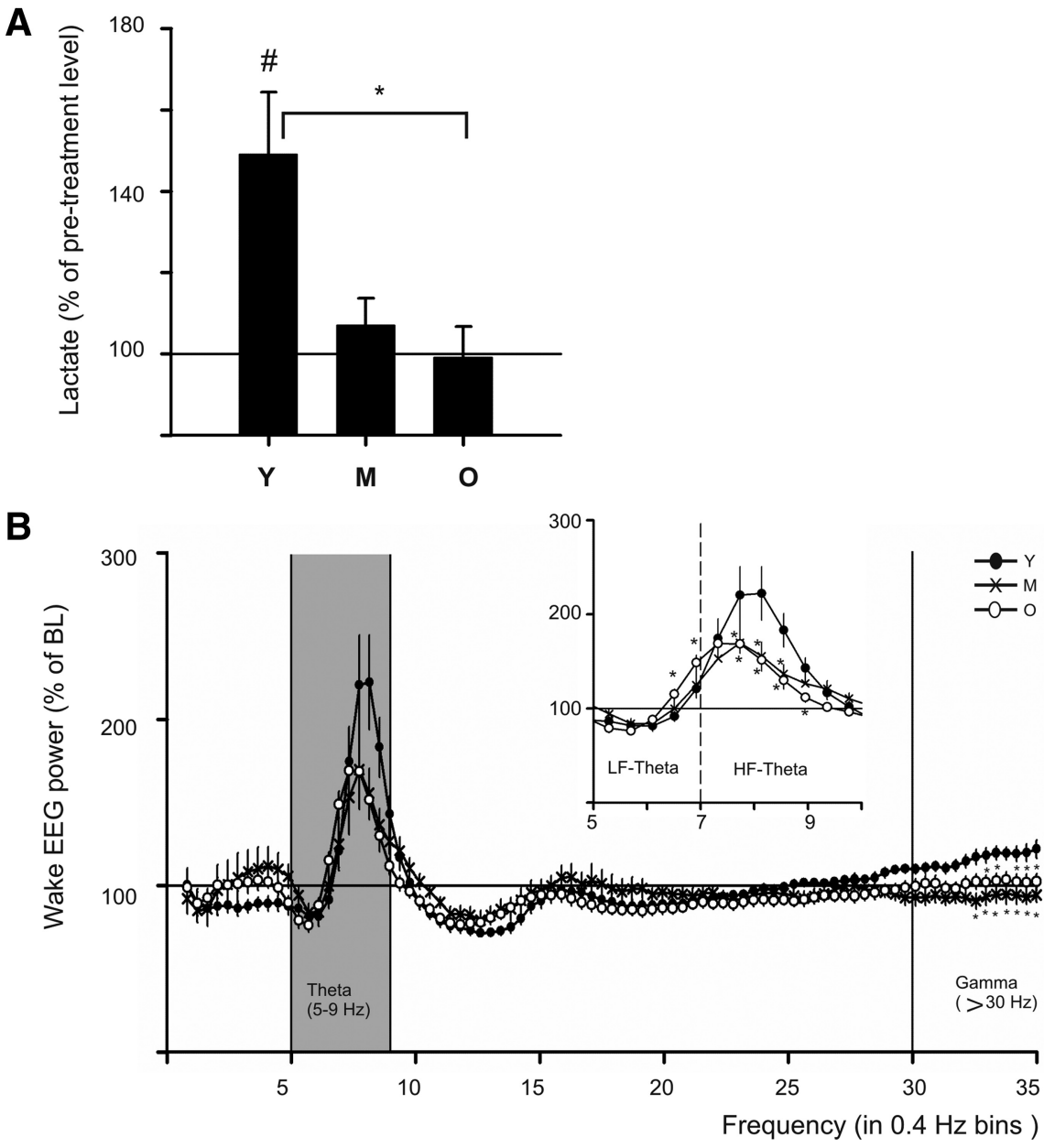

Figure 3. Sleep deprivation. $\boldsymbol{A}, \mathrm{BF}$ lactate. Mean ( \pm SEM) lactate concentration (expressed as percentage of pretreatment level) in the BF during SD in young $\left(n_{\mathrm{Y}}=10\right)$, middle-aged $\left(n_{\mathrm{M}}=8\right)$, and old $\left(n_{0}=12\right)$ rats. The pretreatment level is indicated with $100 \%$ reference line. Statistically significant lactate response [paired $t$ test; $S D$ vs pretreatment; indicated with hash symbol (\#)] was detected during SD in young but not in old or middle-aged rats. There was a statistically significant difference between the 0 and the $Y$ [Kruskal-Wallis one-way ANOVA on ranks, indicated with asterisks $\left.{ }^{*}\right)$ ]. $\boldsymbol{B}$, Waking EEG power spectra. To study the effect of SD on cortical arousal, waking EEG power spectra of SD period were ormalized to the corresponding spectra of the $B L$ day. The mean ( \pm SEM) EEG power (percentage of $B L ; y$-axis) is plotted tire spectral range (frequencies between 0.8 and $35 \mathrm{~Hz}$ in $0.4 \mathrm{~Hz}$ bins; $x$-axis). The $B \mathrm{BL}$ level is indicated with $100 \%$ reference line. The theta $(5-9 \mathrm{~Hz})$ range, in which the major statistical differences (two-way repeated-measures ANOVA followed by Holm-Sidak) between the aged ( $\mathrm{M}$ or 0 ) and the young were found, is highlighted with gray background panel shown in a larger resolution in the top right panel. The individual $0.4 \mathrm{~Hz}$ frequency bins in which a statistica significance $(p<0.05)$ between the aged ( $M$ or 0$)$ and the young was found are indicated with asterisks $\left.{ }^{*}\right)$. Age groups: $\mathrm{Y}(\mathbf{O} ; n=10), \mathrm{M}(X ; n=5), 0(\bigcirc ; n=13)$. In the high-resolution image (right panel), LF theta (5-7 Hz) and the HF theta $(7-9 \mathrm{~Hz})$ are separated by a vertical dashed line.

$\left.10 ; t_{(9)}=2.922 ; p=0.017\right)$. This is in agreement with previous studies from our laboratory (Kalinchuk et al., 2003, 2006b; Wigren et al., 2007). In contrast, significant lactate responses were not detected in middle-aged or old rats, and there was a statistically significant difference in the lactate response between the young and the old (Kruskal-Wallis one-way ANOVA on ranks with Dunn's; $H_{(2)}=9.662 ; p=0.008$ ) (Fig. 3A).

\section{Waking EEG power spectra}

Mean EEG power spectra of the $3 \mathrm{~h}$ SD period compared with $\mathrm{BL}$ spectra of the corresponding time period is shown in figure (Fig. $3 B$ ). During SD, EEG power decreased (compared with BL) in all age groups in the delta $(0.8-4 \mathrm{~Hz})$ and in the LF theta $(5-7 \mathrm{~Hz})$ range, whereas a prominent increase was found in the HF theta (7-9 Hz) range (two-way repeated-measures ANOVA with 
A
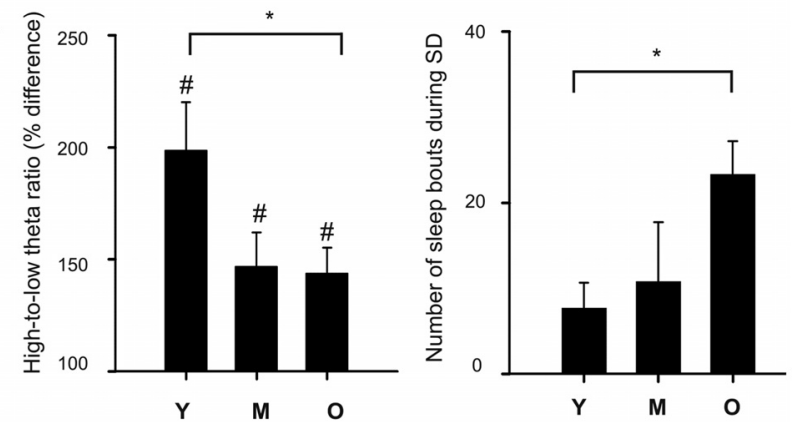

B

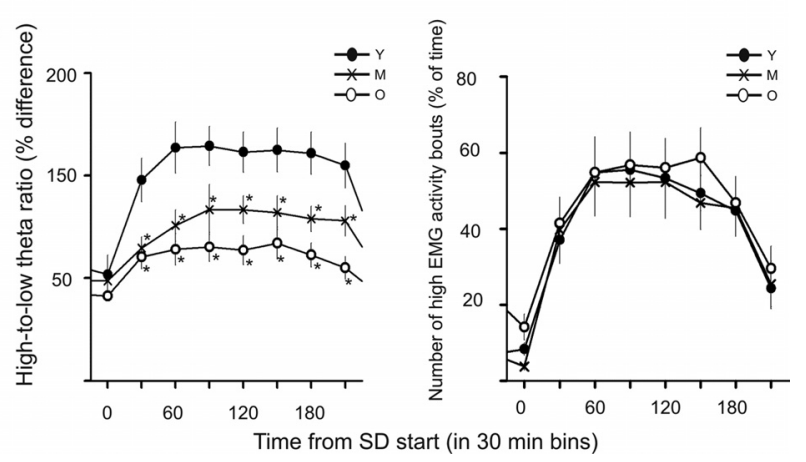

Figure 4. Theta and the "quality" of waking during SD. A, Left panel, High-to-low frequency theta ratio (percentage difference; $y$-axis) in young $(Y)$, middle-aged $(M)$, and old $(0)$ rats during $S D$. Theta ratio increased in all age groups $\left(n_{\mathrm{Y}}=10 ; n_{\mathrm{M}}=5 ; n_{0}=13\right)$ during $S D$ [paired $t$ tests; $p<0.05$; indicated with hash symbols (\#)], but the increase was significantly attenuated in the old compared with the young [one-way ANOVA with Holm-Sidak; $p<0.05$; indicated with asterisks $(*)]$. The theta ratio is shown as group mean ( \pm SEM) calculated over the $3 \mathrm{~h} \mathrm{SD}$ period. Right, Number of sleep bouts during SD. The mean ( \pm SEM) number of sleep bouts (defined as more than one 5 s epoch scored as SWS) in Y, M, and 0 rats during SD. Old rats had significantly more sleep bouts during SD than the young [Kruskal-Wallis one-way ANOVA on ranks with Dunn's; $p<0.05$; indicated with asterisks $\left.\left(^{*}\right)\right]$. B. High-to-low theta ratio (left) and the number of high EMG activity bouts (right) in 30 min time bins during SD. Statistically significant differences (two-way repeated-measures ANOVA followed by Holm-Sidak) between age groups were found only in the waking theta ratio. The individual time bins in which a statistical significance $(p<0.05)$ between the aged (M or 0$)$ and the young was found are indicated with asterisks $\left({ }^{*}\right) . Y(O ; n=10), M(X ; n=5)$, and $0(O ; n=13)$ are shown. The last time point shows the first $30 \mathrm{~min}$ after the end of SD.

Holm-Sidak; treatment by frequency; $\mathrm{Y}, F_{(84)}=12.396, p<$ $0.001 ; \mathrm{M}, F_{(84)}=2.781, p<0.001 ; \mathrm{O}, F_{(84)}=17.929, p<0.001$, respectively). Between age group analysis demonstrated statistically significant attenuations in the middle-aged and old compared with the young in the HF theta and in the gamma $(>30 \mathrm{~Hz})$ range (two-way repeated-measures ANOVA with Holm-Sidak; age by frequency; $\left.F_{(168)}=2.431 ; p<0.001\right)$.

Waking theta and the "quality" of waking during SD

To characterize the behavior (i.e., the quality of waking) of the rats during SD the high-to low-frequency theta ratio (HF theta/LF theta) (Fig. $4 A, B$, left panels) was calculated together with the number of sleep bouts (Fig. $4 A$, right panel) and with the number of high EMG activity bouts (Fig. $4 B$, right panel).

The mean high- to low-frequency theta ratio (Fig. $4 A$, left panel) increased in all age groups (paired $t$ tests; $Y, t_{(9)}=4.567, p=0.001$; $\left.\mathrm{M}, t_{(4)}=3.309, p=0.030 ; \mathrm{O}, t_{(12)}=4.414, p=0.001\right)$, but this increase was significantly attenuated in old rats compared with the young (one-way ANOVA with Holm-Sidak; $F_{(2)}=3.519 ; p=$ 0.045). Old rats had more sleep bouts during SD than the young (Kruskal-Wallis one-way ANOVA on ranks with Dunn's; $H_{(2)}=$ $8.668 ; p=0.013$ ) (Fig. $4 A$, right panel). As rats were always activated when sleep occurred, the maximum sleep bout lengths were only
$0.6 \pm 0.2 \mathrm{~min}$ for the young $(n=10), 0.5 \pm 0.2 \mathrm{~min}$ for the middleaged $(n=5)$, and $1.3 \pm 0.2 \mathrm{~min}$ for the old $(n=13)$.

When the theta ratio (Fig. $4 B$, left panel) and the high EMG activity bouts (Fig. $4 \mathrm{~B}$, right panel) were calculated in $30 \mathrm{~min}$ time bins over the SD period, statistically significant (two-way repeated-measures ANOVA; $F_{(2)}=7.941 ; p=0.002$; followed by Holm-Sidak) age differences were found in all time points in the theta ratio, whereas no differences between age groups were found in the number of high EMG activity bouts.

\section{Correlation of BF lactate release with waking theta}

To test the hypothesis that lactate release in the BF is linked to cortical arousal/active waking (measured with the HF theta increase), we investigated whether there is a statistically significant correlation between lactate increase (percentage of pretreatment level) and the waking theta response (high-to-low waking theta ratio, percentage difference). For this purpose individual lactate samples (collected during the microdialysis period of the SD day and normalized to the pretreatment level; on average, six samples per animal) were matched with EEG data (high-to-low waking EEG theta ratio) of the corresponding 30 min collection period. Statistically significant positive correlation was found in the young group $(n=10)$ between lactate release and waking theta response [Pearson's product moment correlation; $n_{\text {samples }}=42$; correlation coefficient $(r), 0.779 ; p<0.01]$ but not in the middleaged $(n=5)\left(n_{\text {samples }}=29 ; r=0.295 ; p=0.121\right)$ or the old $(n=$ 13) $\left(n_{\text {samples }}=68 ; r=0.037 ; p=0.765\right)$ (Fig. 5$)$.

\section{Glutamatergic stimulation of the BF with NMDA}

As the greatest (and statistically significant) differences in both $\mathrm{BF}$ lactate release and waking theta responses during SD were detected between the young and old, NMDA activation was performed to these age groups only. In line with previous reports (Cape and Jones, 2000; Wigren et al., 2007), waking compared with BL was increased in the young group $(n=5)(68 \pm 4 \%$ increase; paired $t$ test; $\left.t_{(4)}=16.653 ; p<0.001\right)$. In the old group $(n=4)$, waking was increased by $31 \pm 10 \%$, but this increase did not reach statistical significance. There was a statistically significant difference in the amount of waking induced by NMDA between the $\mathrm{Y}$ and the $\mathrm{O}\left(t\right.$ test; $\left.t_{(7)}=3.669 ; p=0.008\right)$.

\section{BF lactate}

In young rats $(n=5)$, glutamatergic stimulation significantly increased BF lactate concentration when compared with the pretreatment level (paired $t$ test; $t_{(4)}=2.975 ; p=0.041$ ), a finding that has been described previously (Wigren et al., 2007). In contrast, glutamatergic stimulation did not evoke significant lactate responses in old rats $(n=4)$.

\section{Waking EEG power spectra}

When the mean EEG power spectra of the $3 \mathrm{~h}$ NMDA infusion period were compared with the corresponding BL power spectra (Fig. 6), we found that in both age groups BF activation significantly attenuated waking EEG power in the delta frequency range and in the LF theta range, whereas an increase was found it in the $\mathrm{HF}$ theta range (two-way repeated-measures ANOVA, treatment by frequency, with Holm-Sidak; $\mathrm{Y}, F_{(84)}=5.499, p<0.001 ; \mathrm{O}$, $\left.F_{(84)}=1.845, p<0.001\right)$. Between age group analysis demonstrated a statistically significant attenuation in the HF theta increase in the old group compared with the young (two-way repeated-measures ANOVA; age by hertz; Holm-Sidak; $F_{(84)}=$ $1.779 ; p<0.001)$ 


\section{Recovery sleep}

To test whether treatments (NMDA, SD) induced recovery sleep, SWS amount and SWS EEG power spectra calculated from the posttreatment EEG recordings were compared with the corresponding time points of the BL day.

\section{SWS amount}

Within an age group statistical analysis (paired $t$ tests) demonstrated significant increases in the time spent in SWS during the first manually scored $3 \mathrm{~h}$ post-SD time period compared with $\mathrm{BL}$ in all age groups $\left(\mathrm{Y}, t_{(9)}=5.289, p<0.01 ; \mathrm{M}, t_{(4)}=11.433\right.$, $\left.p<0.01 ; \mathrm{O}, t_{(12)}=6.381, p<0.001\right)$. Statistically significant differences in the SWS response between the age groups were not found. [The amount of SWS compared with $\mathrm{BL}$ during the recovery night after SD calculated in $1 \mathrm{~h}$ bins can be found in supplemental Table 2 (available at www.jneurosci.org as supplemental material).] After NMDA treatment, a significant increase in SWS compared with $\mathrm{BL}$ was found only in the young group $\left(t_{(4)}=4.355 ; p=0.012\right)$.

SWS EEG power spectra

To assess sleep intensity during recovery sleep, EEG power spectra of the first (manually scored) $3 \mathrm{~h}$ post-SD period were compared with the corresponding BL spectra (Fig. 7). In all age groups, SWS EEG power compared with BL was significantly (two-way repeated-measures ANOVA with Holm-Sidak; treatment by frequency; Y, $F_{(84)}=21.977 ; \mathrm{M}, F_{(84)}=18.880 ; \mathrm{O}$, $\left.F_{(84)}=32.539 ; p<0.001\right)$ increased in the delta frequency range, whereas a significant reduction was found in the frequency ranges $>6.1 \mathrm{~Hz}$. Between age group comparisons demonstrated a statistical significant attenuation in the delta power in the middle-aged and old compared with the young, whereas the SWS EEG of the old and middle-aged rats contained more HF EEG $(>7.3 \mathrm{~Hz})$ power than that of the young (two-way repeated-measures ANOVA with Holm-Sidak; age by frequency; $\left.F_{(168)}=2.662 ; p<0.001\right)$.

\section{Discussion}

We found that the activity-dependent increases in BF lactate and waking EEG theta power were attenuated in aged animals (middle-aged and old) during prolonged waking/sleep deprivation and that neither of these responses could be experimentally induced by glutamatergic stimulation of the BF.

\section{Reduced BF lactate release in aging}

In contrast to young, lactate release did not increase in the $\mathrm{BF}$ during SD in the aged animals (middle-aged and old). Our results are in line with previous human studies showing that cognitive stimulation, which increases lactate in the prefrontal

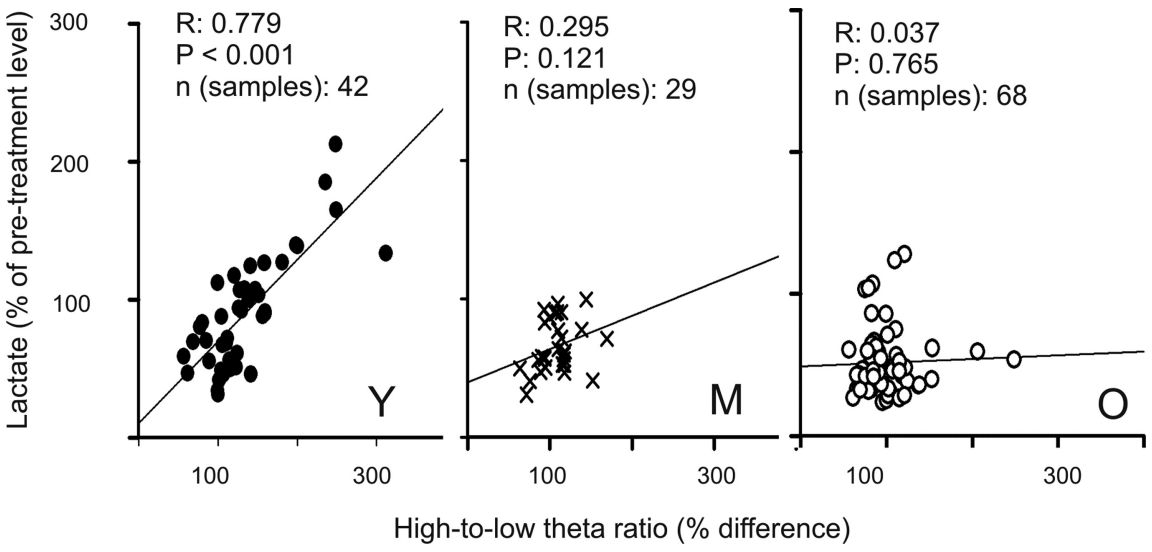

Figure 5. Correlation of BF lactate release with waking theta. Lactate responses (percentage of pretreatment level; $y$-axis) in individual samples collected during the SD day (pretreatment and treatment periods; on average, 6 lactate samples were contributed by 1 rat) were matched with corresponding waking theta responses (high-to-low waking theta ratio; percentage difference; $x$-axis) of the 30 min collection period and plotted separately for each age group: $Y(O), M(X), 0(\bigcirc)\left(n_{Y}=10 ; n_{M}=5 ; n_{0}=13\right)$. Simple regression line is shown for each plot. Statistically significant positive correlation $(p<0.005$; Pearson's product moment correlation) was found in the young but not in the middle-aged or old group.

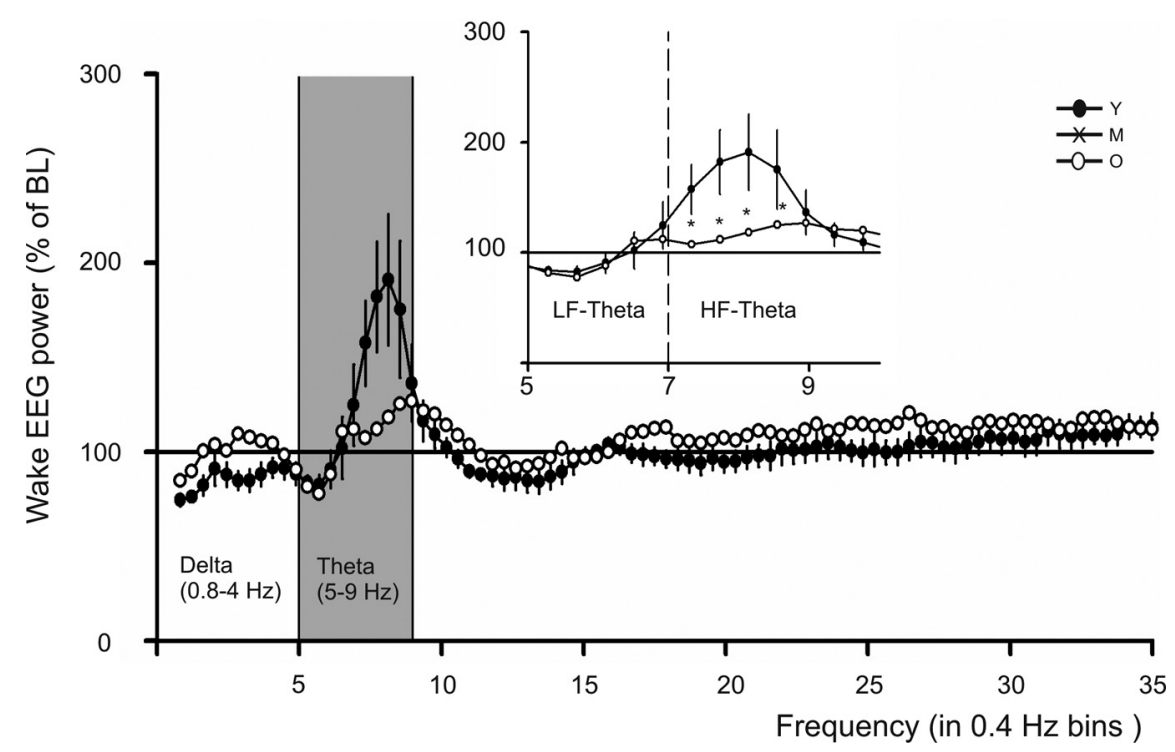

Figure 6. Glutamatergic stimulation of the BF: waking EEG power. The waking EEG power spectra of the treatment period were normalized to the corresponding spectra of the BL day. The mean ( \pm SEM) EEG power (percentage of BL; $y$-axis) is plotted for the entire spectral range (frequencies between 0.8 and $35 \mathrm{~Hz}$ in $0.4 \mathrm{~Hz}$ bins; $x$-axis). The $\mathrm{BL}$ level is indicated with $100 \%$ reference line. The theta $(5-9 \mathrm{~Hz})$ range, in which the major statistical differences (two-way repeated-measures ANOVA followed by HolmSidak) between the $Y$ and 0 were found, is highlighted with gray background panel and shown in a larger resolution in the top right panel. The individual $0.4 \mathrm{~Hz}$ frequency bins in which a statistical significance $(p<0.05)$ between $Y$ and 0 was found are indicated with asterisks $\left(^{*}\right)$. Age groups are as follows: $\mathrm{Y}(\mathbf{O} ; n=5)$ and $0(O ; n=4)$. In the high-resolution image (right), LF theta $(5-7$ $\mathrm{Hz}$ ) and the HF theta $(7-9 \mathrm{~Hz})$ are separated by a vertical dashed line. cortex of young subjects, failed to do so in the aged (Urrila et al., $2003,2004)$. It would be interesting to know whether the attenuation of activity-dependent lactate release is a general phenomenon in the aging brain or whether it is specific for some brain regions only (such as the BF and the prefrontal cortex). The attenuated BF lactate response in our study could have resulted either from reduced sensitivity of the aged BF to excitatory input, reduced release of excitatory transmitters, or from age-related impairments in lactate production or release.

The assumption that age-related attenuation of lactate response is attributable to reduced sensitivity of BF to respond to excitatory input, is supported by previous studies showing age- 


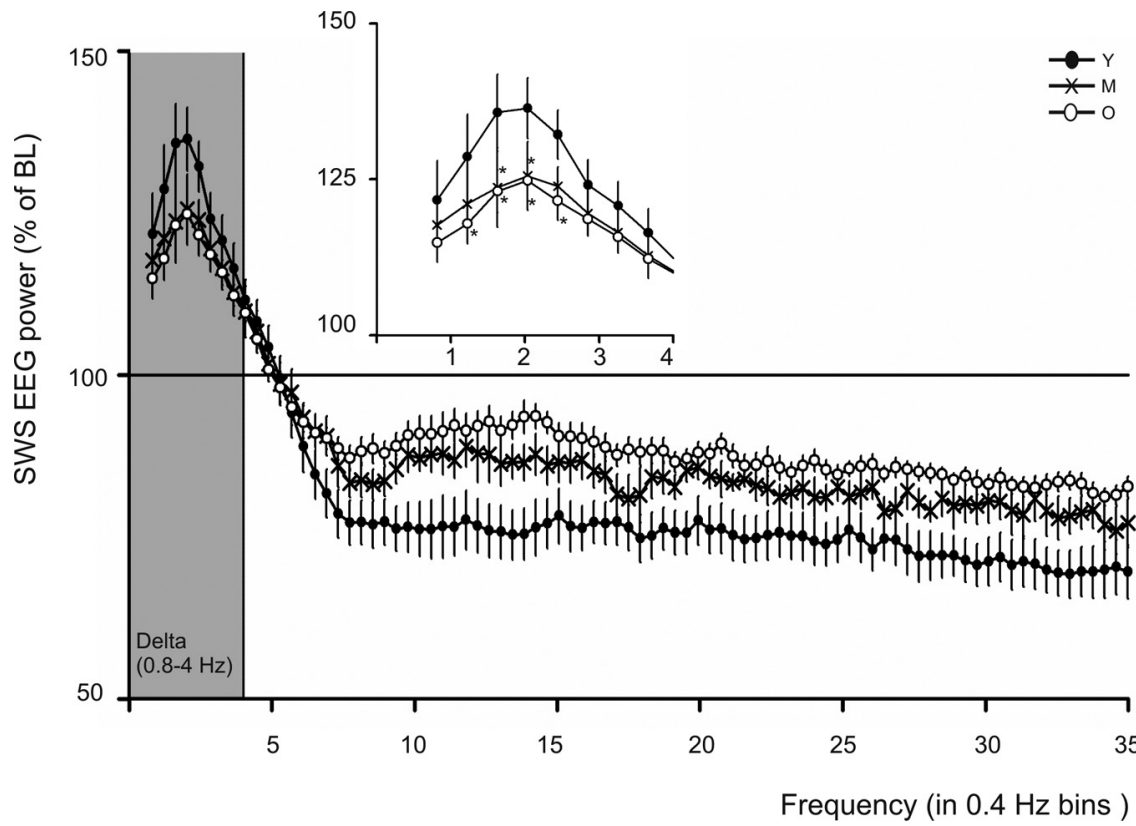

Figure 7. Recovery sleep: SWS EEG power. To assess sleep intensity during the recovery sleep after SD, SWS EEG power spectra of the $3 \mathrm{~h}$ post-SD period were normalized to the corresponding spectra of the BL day. The mean ( \pm SEM) EEG power (percentage of BL; $y$-axis) is plotted for the entire spectral range (frequencies between 0.8 and $35 \mathrm{~Hz}$ in $0.4 \mathrm{~Hz}$ bins; $x$-axis). The BL level is indicated with $100 \%$ reference line. The delta $(0.8-4 \mathrm{~Hz})$ range, in which the major statistical differences (two-way repeatedmeasures ANOVA followed by Holm-Sidak) between the aged $(\mathrm{M}, 0)$ and the young were found, is highlighted with gray background panel and shown in a larger resolution in the top panel. The individual $0.4 \mathrm{~Hz}$ frequency bins in which a statistical significance $(p<0.05)$ between the aged ( $M$ or 0 ) and the young was found in the delta range are indicated with asterisks $(*)$. There were also significant increases in the frequencies $>7.3$ up to $35 \mathrm{~Hz}$ both in the middle-aged and old groups compared with the young (not indicated in the graph). Age groups are as follows: $Y(0 ; n=10), \mathrm{M}(X ; n=5)$, and $0(\bigcirc ; n=13)$.

related reductions in BF stimulation-induced cortical acetylcholine release (Mitsushima et al., 1996; Giovannini et al., 1998; Fadel et al., 1999; Herzog et al., 2003; Sarter and Bruno, 2004). In line with these studies, we found that experimental stimulation of the BF with NMDA did not increase local lactate release or induce enough neuronal activation to significantly increase wakefulness in old rats. Also, several studies have demonstrated age-related decreases in NMDA receptor density and alternations in its function (Gonzales et al., 1991; Segovia et al., 2001).

Another explanation for the lack of activity-dependent lactate release could be the reduced capacity of the aged brain cells to cope with increased energy demand (Toescu and Xiong, 2004). Expression of genes related to energy metabolism are chronically altered in the aged brain, including increased expression of lactate dehydrogenase, an enzyme involved in lactate metabolism (Poon et al., 2006; Pawlyk et al., 2007). Compared with other brain areas, cells in the $\mathrm{BF}$, particularly the cholinergic cells, appear more sensitive to age-related impairments (Sarter and Bruno, 2004; McKinney and Jacksonville, 2005). A recent study found that the age-related increase in expression of genes related to energy production was more pronounced in the cholinergic cells of the $\mathrm{BF}$ than in the cholinergic cells of the brainstem (Baskerville et al., 2008). Thus, if energy production in the BF is challenged already at baseline, it is reasonable to assume that, on activation, the capacity of the BF to further increase energy production and lactate release is reduced.

\section{Waking EEG theta and BF activity}

In rodents, EEG theta activity can be divided into two components: the LF theta $(5-7 \mathrm{~Hz})$ associated with quiet wake and sleepiness and the HF theta $(7-9 \mathrm{~Hz})$ associated with active wake
(Maloney et al., 1997; Vyazovskiy and Tobler, 2005; Young and McNaughton, 2008). We regarded HF EEG theta as a measure of both active waking/cortical arousal and $\mathrm{BF}$ activity because in vivo recordings have shown that the cholinergic cells of the BF are more active during active wake than quiet wake and that they burst in association with EEG theta (Lee et al., 2004, 2005). Furthermore, HF EEG theta power can be increased by experimental activation of the BF (Cape and Jones, 2000; Wigren et al., 2007).

With stimulation of the BF by NMDA and during $3 \mathrm{~h} \mathrm{SD}$, particularly the $\mathrm{HF}$ theta is enhanced, whereas application of NMDA antagonist during SD selectively attenuates HF theta (Wigren et al., 2007). In the present study, the increase in HF theta during SD was reduced in old and middle-aged rats compared with the young. This could be attributable to reduced sensitivity of aged BF to excitatory stimulus, as evidenced by reduced wake promotion and HF theta power increase to NMDA stimulation in the aged. During baseline waking, our old animals had significantly more power in the LF theta range than the young. This finding is consistent with other studies in both humans (van der Hiele et al., 2008) and animals (Colas et al., 2005). Increased waking LF EEG theta is suggested to implicate a reduced arousal level (Schacter, 1977; Cajochen et al., 1995, 2001, 2002; Lorenzo et al., 1995; Aeschbach et al., 1997, 1999; Finelli et al., 2000; Lafrance and Dumont, 2000; Strijkstra et al., 2003). Reduced baseline arousal could reduce the capacity of the old to increase active wake (a shift from low- to high-frequency theta enriched waking), particularly during SD.

\section{Correlation between BF lactate release and HF EEG theta increase}

To further substantiate the assumption that lactate release in the BF is linked to active waking and HF theta, we found a strong positive correlation between BF lactate release and HF EEG theta increase in young animals, which was lost in the aged. Together, our results show that both measures of BF activation, local lactate release and HF EEG theta, are reduced in aging.

\section{Implications for sleep homeostasis}

Sleep is governed by a homeostatic process in which duration and quality of waking regulate subsequent sleep (Borbély, 1982; Huber et al., 2007). In our aged animals, SWS delta $(0.5-4 \mathrm{~Hz})$ power, a marker of sleep intensity and homeostatic sleep drive (Achermann and Borbély, 2003), was reduced in baseline and its increase in response to SD was attenuated. This finding is in line with other studies with aged rats (Mendelson and Bergmann, 2000; Shiromani et al., 2000). In addition, we found age differences also in the higher frequency ranges: in all age groups, frequencies $>7.3 \mathrm{~Hz}$ were attenuated in the recovery SWS EEG compared with $\mathrm{BL}$, but this attenuation was reduced in the aged. In other words, during recovery sleep, aged animals had less delta activity and more high frequency activity than the young. As delta 
activity is an indication of sleep intensity and the higher frequencies are an indication of cortical arousal, these results further emphasize the fact that, in aging, recovery sleep intensity is attenuated.

The mechanisms contributing to the age-related attenuation in sleep homeostasis are not well understood. There are two probable causes for reduced recovery sleep in aging: (1) the capacity to produce sleep is reduced (Klerman and Dijk, 2008) and/or (2) accumulation of homeostatic sleep pressure is reduced.

In young animals, increases in the extracellular levels of the endogenous sleep factors adenosine and nitric oxide (NO) in the BF during SD are repeatedly reported to induce sleep (PorkkaHeiskanen et al., 1997, 2000; Basheer et al., 2004; MurilloRodriguez et al., 2004; Kalinchuk et al., 2006a,b). In our previous study, we found aging related attenuations in the levels of adenosine and $\mathrm{NO}$ in the $\mathrm{BF}$ during $\mathrm{SD}$, suggesting a reduction in the buildup of homeostatic sleep pressure (Rytkönen et al., 2008). Furthermore, local infusion of NO donor into the BF failed to increase sleep intensity in old rats, as it did in the young, suggesting that also the sensitivity of the aged BF to sleep-inducing factors is reduced.

The present study demonstrated that cortical arousal (as measured by EEG theta and gamma power) was reduced in aged rats during SD. Previous studies have shown that wakefulness enriched with high levels of active wake and HF EEG theta is more potent in increasing sleep pressure and recovery sleep delta power than the same amount of quiet waking (Huber et al., 2007; Wigren et al., 2007). Thus, the reduced adenosine and NO responses during SD and the attenuation of homeostatic sleep response in recovery sleep could be attributable to the fact that aged animals spent less time in active wake.

Sleep problems are becoming increasingly prevalent in the modern society, particularly when the population ages. Understanding of the cellular mechanisms contributing to these problems is crucial for appropriate treatment. Our results suggest that an age-related attenuation in BF function leads to reduced cortical arousal, particularly during prolonged waking. As quality of waking is important in regulating subsequent sleep, reduction in cortical arousal during waking may contribute to the age-related reduction in sleep intensity.

\section{References}

Achermann P, Borbély AA (2003) Mathematical models of sleep regulation. Front Biosci 8:s683-s693.

Aeschbach D, Matthews JR, Postolache TT, Jackson MA, Giesen HA, Wehr TA (1997) Dynamics of the human EEG during prolonged wakefulness: evidence for frequency-specific circadian and homeostatic influences. Neurosci Lett 239:121-124.

Aeschbach D, Matthews JR, Postolache TT, Jackson MA, Giesen HA, Wehr TA (1999) Two circadian rhythms in the human electroencephalogram during wakefulness. Am J Physiol 277:R1771-R1779.

Armstrong DM, Sheffield R, Buzsaki G, Chen KS, Hersh LB, Nearing B, Gage FH (1993) Morphologic alterations of choline acetyltransferase-positive neurons in the basal forebrain of aged behaviorally characterized Fisher 344 rats. Neurobiol Aging 14:457-470.

Basheer R, Strecker RE, Thakkar MM, McCarley RW (2004) Adenosine and sleep-wake regulation. Prog Neurobiol 73:379-396.

Baskerville KA, Kent C, Personett D, Lai WR, Park PJ, Coleman P, McKinney M (2008) Aging elevates metabolic gene expression in brain cholinergic neurons. Neurobiol Aging 29:1874-1893.

Benington JH, Heller HC (1995) Restoration of brain energy metabolism as the function of sleep. Prog Neurobiol 45:347-360.

Borbély AA (1982) A two process model of sleep regulation. Hum Neurobiol 1:195-204.

Buysse DJ, Browman KE, Monk TH, Reynolds CF 3rd, Fasiczka AL, Kupfer DJ
(1992) Napping and 24-hour sleep/wake patterns in healthy elderly and young adults. J Am Geriatr Soc 40:779-786.

Caesar K, Hashemi P, Douhou A, Bonvento G, Boutelle MG, Walls AB, Lauritzen M (2008) Glutamate receptor-dependent increments in lactate, glucose and oxygen metabolism evoked in rat cerebellum in vivo. J Physiol 586:1337-1349.

Cajochen C, Brunner DP, Kräuchi K, Graw P, Wirz-Justice A (1995) Power density in theta/alpha frequencies of the waking EEG progressively increases during sustained wakefulness. Sleep 18:890-894.

Cajochen C, Knoblauch V, Kräuchi K, Renz C, Wirz-Justice A (2001) Dynamics of frontal EEG activity, sleepiness and body temperature under high and low sleep pressure. Neuroreport 12:2277-2281.

Cajochen C, Wyatt JK, Czeisler CA, Dijk DJ (2002) Separation of circadian and wake duration-dependent modulation of EEG activation during wakefulness. Neuroscience 114:1047-1060.

Cajochen C, Münch M, Knoblauch V, Blatter K, Wirz-Justice A (2006) Agerelated changes in the circadian and homeostatic regulation of human sleep. Chronobiol Int 23:461-474.

Cape EG, Jones BE (2000) Effects of glutamate agonist versus procaine microinjections into the basal forebrain cholinergic cell area upon gamma and theta EEG activity and sleep-wake state. Eur J Neurosci 12:2166-2184.

Carskadon MA, Brown ED, Dement WC (1982) Sleep fragmentation in the elderly: relationship to daytime sleep tendency. Neurobiol Aging 3:321-327.

Cirelli C (2006) Cellular consequences of sleep deprivation in the brain. Sleep Med Rev 10:307-321.

Colas D, Cespuglio R, Sarda N (2005) Sleep wake profile and EEG spectral power in young or old senescence accelerated mice. Neurobiol Aging 26:265-273.

Fadel J, Sarter M, Bruno JP (1999) Age-related attenuation of stimulated cortical acetylcholine release in basal forebrain-lesioned rats. Neuroscience 90:793-802.

Finelli LA, Baumann H, Borbély AA, Achermann P (2000) Dual electroencephalogram markers of human sleep homeostasis: correlation between theta activity in waking and slow-wave activity in sleep. Neuroscience 101:523-529.

Franken P, Dijk DJ, Tobler I, Borbély AA (1991) Sleep deprivation in rats: effects on EEG power spectra, vigilance states, and cortical temperature. Am J Physiol 261:R198-R208.

Giovannini MG, Bartolini L, Kopf SR, Pepeu G (1998) Acetylcholine release from the frontal cortex during exploratory activity. Brain Res 784:218-227.

Gonzales RA, Brown LM, Jones TW, Trent RD, Westbrook SL, Leslie SW (1991) $\mathrm{N}$-methyl-D-aspartate mediated responses decrease with age in Fischer 344 rat brain. Neurobiol Aging 12:219-225.

Grob RL (1985) Modern practice of gas chromatography. New York: Wiley. Hallström A, Carlsson A, Hillered L, Ungerstedt U (1989) Simultaneous determination of lactate, pyruvate, and ascorbate in microdialysis samples from rat brain, blood, fat, and muscle using high-performance liquid chromatography. J Pharmacol Methods 22:113-124.

Herzog CD, Nowak KA, Sarter M, Bruno JP (2003) Microdialysis without acetylcholinesterase inhibition reveals an age-related attenuation in stimulated cortical acetylcholine release. Neurobiol Aging 24:861-863.

Hu Y, Wilson GS (1997) A temporary local energy pool coupled to neuronal activity: fluctuations of extracellular lactate levels in rat brain monitored with rapid-response enzyme-based sensor. J Neurochem 69:1484-1490.

Huber R, Tononi G, Cirelli C (2007) Exploratory behavior, cortical BDNF expression, and sleep homeostasis. Sleep 30:129-139.

Jones BE (2008) Modulation of cortical activation and behavioral arousal by cholinergic and orexinergic systems. Ann N Y Acad Sci 1129:26-34.

Kahana MJ, Seelig D, Madsen JR (2001) Theta returns. Curr Opin Neurobiol 11:739-744.

Kalinchuk AV, Urrila AS, Alanko L, Heiskanen S, Wigren HK, Suomela M, Stenberg D, Porkka-Heiskanen T (2003) Local energy depletion in the basal forebrain increases sleep. Eur J Neurosci 17:863-869.

Kalinchuk AV, Stenberg D, Rosenberg PA, Porkka-Heiskanen T (2006a) Inducible and neuronal nitric oxide synthases (NOS) have complementary roles in recovery sleep induction. Eur J Neurosci 24:1443-1456.

Kalinchuk AV, Lu Y, Stenberg D, Rosenberg PA, Porkka-Heiskanen T (2006b) Nitric oxide production in the basal forebrain is required for recovery sleep. J Neurochem 99:483-498. 
Kaur S, Junek A, Black MA, Semba K (2008) Effects of ibotenate and 192IgG-saporin lesions of the nucleus basalis magnocellularis/substantia innominata on spontaneous sleep and wake states and on recovery sleep after sleep deprivation in rats. J Neurosci 28:491-504.

Klerman EB, Dijk DJ (2008) Age-related reduction in the maximal capacity for sleep-implications for insomnia. Curr Biol 18:1118-1123.

Kuhr WG, Korf J (1988) Extracellular lactic acid as an indicator of brain metabolism: continuous on-line measurement in conscious, freely moving rats with intrastriatal dialysis. J Cereb Blood Flow Metab 8:130-137.

Lafrance C, Dumont M (2000) Diurnal variations in the waking EEG: comparisons with sleep latencies and subjective alertness. J Sleep Res 9:243-248.

Lee MG, Manns ID, Alonso A, Jones BE (2004) Sleep-wake related discharge properties of basal forebrain neurons recorded with micropipettes in head-fixed rats. J Neurophysiol 92:1182-1198.

Lee MG, Hassani OK, Alonso A, Jones BE (2005) Cholinergic basal forebrain neurons burst with theta during waking and paradoxical sleep. J Neurosci 25:4365-4369.

Lorenzo I, Ramos J, Arce C, Guevara MA, Corsi-Cabrera M (1995) Effect of total sleep deprivation on reaction time and waking EEG activity in man. Sleep 18:346-354.

Maloney KJ, Cape EG, Gotman J, Jones BE (1997) High-frequency gamma electroencephalogram activity in association with sleep-wake states and spontaneous behaviors in the rat. Neuroscience 76:541-555.

Manfridi A, Brambilla D, Mancia M (1999) Stimulation of NMDA and AMPA receptors in the rat nucleus basalis of Meynert affects sleep. Am J Physiol 277:R1488-R1492.

McKinney M, Jacksonville MC (2005) Brain cholinergic vulnerability: relevance to behavior and disease. Biochem Pharmacol 70:1115-1124.

Mendelson WB, Bergmann BM (2000) Age-dependent changes in recovery sleep after 48 hours of sleep deprivation in rats. Neurobiol Aging 21:689-693.

Mitsushima D, Mizuno T, Kimura F (1996) Age-related changes in diurnal acetylcholine release in the prefrontal cortex of male rats as measured by microdialysis. Neuroscience 72:429-434.

Murchison D, Griffith WH (2007) Calcium buffering systems and calcium signaling in aged rat basal forebrain neurons. Aging Cell 6:297-305.

Murillo-Rodriguez E, Blanco-Centurion C, Gerashchenko D, Salin-Pascual RJ, Shiromani PJ (2004) The diurnal rhythm of adenosine levels in the basal forebrain of young and old rats. Neuroscience 123:361-370.

Ohayon MM, Carskadon MA, Guilleminault C, Vitiello MV (2004) Metaanalysis of quantitative sleep parameters from childhood to old age in healthy individuals: developing normative sleep values across the human lifespan. Sleep 27:1255-1273.

Page KJ, Saha A, Everitt BJ (1993) Differential activation and survival of basal forebrain neurons following infusions of excitatory amino acids: studies with the immediate early gene c-fos. Exp Brain Res 93:412-422.

Parikh V, Sarter M (2008) Cholinergic mediation of attention: contributions of phasic and tonic increases in prefrontal cholinergic activity. Ann N Y Acad Sci 1129:225-235.

Pawlyk AC, Ferber M, Shah A, Pack AI, Naidoo N (2007) Proteomic analysis of the effects and interactions of sleep deprivation and aging in mouse cerebral cortex. J Neurochem 103:2301-2313.

Paxinos G, Watson C (1998) The rat brain in stereotaxic coordinates. San Diego: Academic.

Pellerin L, Bouzier-Sore AK, Aubert A, Serres S, Merle M, Costalat R, Magistretti PJ (2007) Activity-dependent regulation of energy metabolism by astrocytes: an update. Glia 55:1251-1262.

Poon HF, Vaishnav RA, Getchell TV, Getchell ML, Butterfield DA (2006) Quantitative proteomics analysis of differential protein expression and oxidative modification of specific proteins in the brains of old mice. Neurobiol Aging 27:1010-1019.

Porkka-Heiskanen T, Strecker RE, Thakkar M, Bjorkum AA, Greene RW, McCarley RW (1997) Adenosine: a mediator of the sleep-inducing effects of prolonged wakefulness. Science 276:1265-1268.

Porkka-Heiskanen T, Strecker RE, McCarley RW (2000) Brain sitespecificity of extracellular adenosine concentration changes during sleep deprivation and spontaneous sleep: an in vivo microdialysis study. Neuroscience 99:507-517.
Porkka-Heiskanen T, Alanko L, Kalinchuk A, Stenberg D (2002) Adenosine and sleep. Sleep Med Rev 6:321-332.

Prichard J, Rothman D, Novotny E, Petroff O, Kuwabara T, Avison M, Howseman A, Hanstock C, Shulman R (1991) Lactate rise detected by ${ }^{1} \mathrm{H}$ NMR in human visual cortex during physiologic stimulation. Proc Natl Acad Sci U S A 88:5829-5831.

Ros J, Pellerin L, Magara F, Dauguet J, Schenk F, Magistretti PJ (2006) Metabolic activation pattern of distinct hippocampal subregions during spatial learning and memory retrieval. J Cereb Blood Flow Metab 26:468-477.

Rytkönen KM, Wigren HK, Kostin A, Porkka-Heiskanen T, Kalinchuk AV (2008) Nitric oxide mediated recovery sleep is attenuated with aging. Neurobiol Aging, in press.

Sappey-Marinier D, Calabrese G, Fein G, Hugg JW, Biggins C, Weiner MW (1992) Effect of photic stimulation on human visual cortex lactate and phosphates using ${ }^{1} \mathrm{H}$ and ${ }^{31} \mathrm{P}$ magnetic resonance spectroscopy. J Cereb Blood Flow Metab 12:584-592.

Sarter M, Bruno JP (2004) Developmental origins of the age-related decline in cortical cholinergic function and associated cognitive abilities. Neurobiol Aging 25:1127-1139.

Schacter DL (1977) EEG theta waves and psychological phenomena: a review and analysis. Biol Psychol 5:47-82.

Schliebs R, Arendt T (2006) The significance of the cholinergic system in the brain during aging and in Alzheimer's disease. J Neural Transm 113:1625-1644.

Segovia G, Porras A, Del Arco A, Mora F (2001) Glutamatergic neurotransmission in aging: a critical perspective. Mech Ageing Dev 122:1-29.

Shiromani PJ, Lu J, Wagner D, Thakkar J, Greco MA, Basheer R, Thakkar M (2000) Compensatory sleep response to $12 \mathrm{~h}$ wakefulness in young and old rats. Am J Physiol Regul Integr Comp Physiol 278:R125-R133.

Stenberg D, Litonius E, Halldner L, Johansson B, Fredholm BB, PorkkaHeiskanen T (2003) Sleep and its homeostatic regulation in mice lacking the adenosine A1 receptor. J Sleep Res 12:283-290.

Strijkstra AM, Beersma DG, Drayer B, Halbesma N, Daan S (2003) Subjective sleepiness correlates negatively with global alpha $(8-12 \mathrm{~Hz})$ and positively with central frontal theta $(4-8 \mathrm{~Hz})$ frequencies in the human resting awake electroencephalogram. Neurosci Lett 340:17-20.

Tobler I, Borbély AA (1990) The effect of 3-h and 6-h sleep deprivation on sleep and EEG spectra of the rat. Behav Brain Res 36:73-78.

Toescu EC, Xiong J (2004) Metabolic substrates of neuronal aging. Ann N Y Acad Sci 1019:19-23.

Urrila AS, Hakkarainen A, Heikkinen S, Vuori K, Stenberg D, Häkkinen AM, Lundbom N, Porkka-Heiskanen T (2003) Metabolic imaging of human cognition: an $\mathrm{fMRI} /{ }^{1} \mathrm{H}-\mathrm{MRS}$ study of brain lactate response to silent word generation. J Cereb Blood Flow Metab 23:942-948.

Urrila AS, Hakkarainen A, Heikkinen S, Vuori K, Stenberg D, Häkkinen AM, Lundbom N, Porkka-Heiskanen T (2004) Stimulus-induced brain lactate: effects of aging and prolonged wakefulness. J Sleep Res 13:111-119.

van der Hiele K, Bollen EL, Vein AA, Reijntjes RH, Westendorp RG, van Buchem MA, Middelkoop HA, van Dijk JG (2008) EEG markers of future cognitive performance in the elderly. J Clin Neurophysiol 25:83-89.

Vinogradova OS (1995) Expression, control, and probable functional significance of the neuronal theta-rhythm. Prog Neurobiol 45:523-583.

Vyazovskiy VV, Tobler I (2005) Theta activity in the waking EEG is a marker of sleep propensity in the rat. Brain Res 1050:64-71.

Vyazovskiy VV, Cirelli C, Tononi G, Tobler I (2008) Cortical metabolic rates as measured by 2-deoxyglucose-uptake are increased after waking and decreased after sleep in mice. Brain Res Bull 75:591-597.

Wigren HK, Porkka-Heiskanen T (2009) Inducible nitric oxide synthase and AMP-activated protein kinase in basal forebrain during prolonged waking. Neuroreport 20:97-101.

Wigren HK, Schepens M, Matto V, Stenberg D, Porkka-Heiskanen T (2007) Glutamatergic stimulation of the basal forebrain elevates extracellular adenosine and increases the subsequent sleep. Neuroscience 147: 811-823.

Young CK, McNaughton N (2008) Coupling of theta oscillations between anterior and posterior midline cortex and with the hippocampus in freely behaving rats. Cereb Cortex 19:24-40. 